\title{
\begin{tabular}{|c|c|}
\hline JARNAL EKONOMI DAN MANAJEMEN \\
P-ISSN: 2598-9022/ E-ISSN: 2598-9618 \\
Available at: http://e-journal.unipma.ac.id/index.php/capital
\end{tabular}
}

\section{Pengaruh Experiental Marketing dan Promosi Terhadap Kepuasan Konsumen pada Laki Lucky Babershop}

\author{
Sri Mulyani ${ }^{1}$, Intisari Haryanti ${ }^{2}$ \\ Ekonomi Manajemen Sekolah Tinggi Ilmu Ekonomi (STIE) Bima \\ $\underline{\text { Srim53353@gmail.com }}^{1}$, intisariharyanti@gmail.com ${ }^{2}$
}

\begin{abstract}
Having an attractive appearance, no longer the only dream of women, men also want an attractive appearance and trendy style. no wonder if in this era, you find men who like to go to beauty salons and haircuts like barbershop. This study aims to determine the effect of experiantial marketing and promotion on consumer satisfaction in Lucky Barbershop Men. This is an associative study with an unknown population, and a sample of 96 people. The analysis was carried out 2 times, because the 15th item of customer satisfaction was declared invalid, so that the next test, researchers used only 14 instrument items. The findings are: experiential marketing and promotion on lucky barbershop men have a positive and significant effect on customer satisfaction both partially and together.
\end{abstract}

Keywords: Experiantial Marketing, Promotion, and Consumer Satisfaction.

\begin{abstract}
Abstrak
Memiliki penampilan yang menarik, bukan lagi idaman para wanita semata, kaum lelaki juga menginginkan penampilan yang menarik dan bergaya trendy. tak heran jika di era sekarang ini, anda menemukan kaum pria yang gemar mendatangi salon kecantikan dan salon potong rambut seperti barbershop. tujuan dari penelitian ini untuk mengetahui pengaruh Experiantial marketing dan promosi terhadap kepuasan konsumen pada Laki Lucky Barbershop. ini merupakan penelitian Asosiatif dengan jumlah populasi pada yang tidak diketahui, dan sampel sejumlah 96 orang. analisis dilakukan sebanyak 2 kali,karena item ke 15 dari kepuasan konsumen, dinyatakan tidak valid, sehingga uji selanjutnya, peneliti menggunakan 14 item instrumen saja. Hasiltemuannya adalah :experiential marketing dan promosi pada Laki lucky barbershop secara positif dan signifikan memberikan pengaruh terhadap kepuasan konsumen baik parsial maupun bersama-sama.
\end{abstract}

Kata kunci : Experiantial Marketing, Promosi, Dan Kepuasan Konsumen. 


\section{PENDAHULUAN}

Memiliki penampilan yang menarik, bukan lagi idaman para wanita semata, kaum lelaki juga menginginkan penampilan yang menarik dan bergaya trendy. tak heran jika di era sekarang ini, anda menemukan kaum pria yang gemarmendatangi salon kecantikan dan salon potong rambut seperti barbeshop. Usaha barbershop atau salon potong rambut pria pun mulai dikenal dan dijalani sebagai salah satu usaha yang cukup menjanjikan dikota wilayah timur indonesia, Bima.

Barbershop merupakan usaha yang bergerak dibidang jasa. Salon khusus laki-laki ini ada karena laki-laki mulai sadar penampilan, kerapian, tata berpakaian sampai pada kebersihan wajah dan tatanan rambut. Perubahan dan perkembangan zaman membuat usaha inipun mengalami kemajuan, terbukti beberapa barbershop pun mulai ditemukan di Bima.

Laki Lucky Barberhop salah satunya. Kemunculan barbershop ini, Sebagai salah satu salon potong rambut yang di anggap berkelas bagi kaum pria khususnya di bima.bagi mereka, potong rambut pada salon barbershop, memberikan kesan elit dan menyenangkan, jika dibandingkan potong rambut pada salon potong rambut biasa. alasannya berbeda beda, ada yang mengatakan karena tempatnya terlihat bagus dan berkelas, ada juga yang beralasan karena mengikuti trend untuk potong rambut di barbershop. Laki Lucky Barberhop berdiri hampir 3 tahun lamanya dikota bima, menyediakan layanan potong rambut, gunting cuci scrub, shaving ( treatment menghilangkan bulu dengan alat cukur), hair tatoo (membuat tampilan rambut berbeda dengan kombinasi dari undercut dan kreativitas), creambath (perawatan rambut dan kepala secara basah dengan menggunakan bantuan alat kosmetik dan handuk agar rambut dalam keadaan bersih dan sehat). Pada Laki Lucky Barbershop ini setelah dilakukan pemotongan rambut konsumen akan dimanjakan dengan pijatan relaksasi oleh karyawan dan jika ingin bersih dari sisa-sisa rambut konsumen juga bisa menggunakan jasa cuci scrub untuk menghilangkan rambut yang menempel, selain itu ada pula treatment atau perawatan seperti toning (pewarnaan rambut), dan facial. Selain iu mereka juga memiliki berbagai macam merek pomade yang bisa dicoba untuk kaum laki-laki, disana setiap pomade memiliki discount untuk masing-masing setiap merek pomade.

Selama kurun waktu 3 tahun promosi yang dilakukan oleh laki lucky berbershop yaitu melalui media facebook dan instagram, promosi yang pernah dilakukan yaitu pada tahun 2017 laki lucky barbershop melakukan promo kerjasama dengan BPJS Kesehatan yaitu apabila konsumen yang memiliki kartu JKN-KIS yang masih aktif akan mendapatkan discount $20 \%$ untuk All treatment minimal service Rp 40.000,-. Namun promosi tersebut saat 
ini sudah tidak diberlakukan lagi, dan dalam kurun waktu dua tahun terakhir ini Laki Lucky Barbershop kurang mempromosikan jasanya dimedia online, juga jarang mengikuti eventevent yang ada,ini dikarenakan banyaknya barbershop yang bermunculan di bima. selain itu ada beberapa keluhan dari konsumen terkait perawatannya, yaitu bau obat perawatan yang menyengat yang mengganggu penciuman meski difasilitasi AC. setiap konsumen yang melakukan treatment menggunakan obat perawatan, pasti akan tidak diberikan masker agar tidak terlalu menghirup aroma obat kosmetik yang menyengat.keluhan lainnya adalah, karyawannya rata rata adalah laki laki sehingga tidak terlalu menarik hati konsumennya. Hal ini menyebabkan kesan layanan yang belum baik dan tidak memuaskan para konsumennya.menurut penuturan dari sang pemilik, mereka memang mengalami penurunan jumlah konsumen, tetapi tidak semuanya. ada juga beberapa dari konsumen sebelumnya yang merasa puas, sekarang sudah menjadi pelanggan tetap.

\section{TINJAUAN PUSTAKA}

\section{Experiential Marketing}

Dalam penelitian ini ada beberapa pengertian Experiential Marketing menurut beberapa ahli adalah sebagai berikut :

Menurut Honanta dan Anandya (2010), mengungkapkan bahwa perilaku pasca pembelian dipengaruhi oleh banyak faktor, salah satunya adalah Experiential Marketing.Menurutnya, Experiential Marketing lebih difokusdengan cara memberikan pengalaman yang berkesan pada pembeli.Sementara Andreani (2007) dalam Valentino dan Drs. Sugiyono (2014) menjelaskan ekperiental marketing adalah kegiatan mensugesti emosi konsumen.Tujuannya dapat memberikan emosi yang baik dan pikiran yang baik tentang penjual sebingga berkesan dan membuat konsumen tersebut berniat untuk membeli kembali atau loyal (Kartajaya, 2004).

Sebelumnya, ditahun 1997, Liljander dan Strandvik Nunes dan Cespedes (2003) mengungkapkanada sisi emosional yang mampu memberikan kepuasan pada konsumen. Nunes dan Cespedes (2003) lebih lanjut menyebutkan, melupakan sisi emosional dan memfokuskan pada bentuk fisik produk semata, lambat laun akan berdampak pada kehilangan konsumen kedepannya.Experiantial Marketing harus fokus untuk menjadikan konsumen sebagai raja baik logic juga emosional (Schmitt, 1999). Sehingga dapat disimpulkan bahwa Experiential Marketing merupakan cara yang digunakan oleh pemilik 
usaha dalam memenuhi kepuasan konsumen dengan cara memberikan pengalaman pertama dan menggoda yang melekat diingatannya.

Menurut Hasan (2013) ada 5 indikator dari Experiantial Marketing, yaitu :

\section{Indera (Sense)}

Merupakan penciptaan pengalaman melalui indera manusia, yaitu : mata, telinga, hidung, mulut dan kulit. Faktor ini mampu menciptakan keutuhan sebuah kesan, lebih kepada simbol-simbol verbal dan visual

2. Perasaan (Feel)

Faktor iniadalah tentang emosi dan perasaan konsumen.Hal ini penting karena berkenaan dengan apa yang dirasakan konsumen untuk membentuk pengalaman yang dirasakannya terhadap merek tertentu. Perasaan yang baik yang dirasakan saat pemakaian produk, akan membuat konsumen mengingat produk tersebut atau mereknya atau bahkan perusahaan yang memproduksinya.

\section{Pikiran (Think)}

Pengalaman dan pemecahan masalah membuat konsumen untuk berpikir secara kreatifdan kolaboratif.think akan menuntut konsumen tersebut berpikit kreatif dan juga positif baik tentang perusahaan maupun tentang mereknya.

4. Perilaku dan kebiasaan (Act)

Faktor act terjadi secara pribadi, terlebih jika pengalaman tersebut berkaitan dengan kepribadian kita, namunfaktor act terjadi dari interaksi publik.

\section{Pertalian/hubungan (Relate)}

Menciptakan hubungan adalah point utama dalam berbisnis.hubungan yang terjalin dengan baik, akan memberikan kemudahan bagi pengusaha atau perusahaan untuk berkembang, karena menciptakan hubungan dengan menjalin hubungan emoosional yang baik, biayanya lebih mudah, dibandingkan dengan mencari konsumen baru. hubungan yang baik konsumen dengan perusahaan juga dapat membuat konsumen selalu ingat akan merek dan layanan yang diberikan perusahaan.

\section{Promosi}

Promosi menjadi sangat penting dalam keberhasilan usaha dan selalu menjadi topik yang menarik untuk dibahas.Ada beberapa defenisi Promosi menurut beberapa ahli. Kotler \& Armstrong (2001) mendefenisikan Promosi sebagai fungsi pembujukan, pemberitahuan, yang berimbas pada keputusan konsumen.Berikutnya Tjiptono (2008) mengungkapkan promosi 
merupakan keuntungan bagi konsumen karena dalam promosi ada sejumlah tawaran misalnya pemberian diskon.Promosi menjadi cara mengkomunikasikan informasi potensial untuk menstimulus sikap dan perilaku pembeli.(Canon, Perrealult dan McCarthy, 2009).

Dalam Bukunya, Drs. M. Mursid (2010) mendukung pendapat Canon (2010) dimana dia menjelaskan bahwa Promosi adalah komunikasi persuasif. Kemudian Suryadi (2011) mendefinisikan Promosi sebagai penyampaian informasi dengan komunikasi tentang suatu produk agar si konsumen mengerahui kualitas, dan mutu produk sehingga konsumen tersebut menjadi pelanggan tetap mereka. Indikator promosi dalam buku pemasaran Drs. M. Mursid (2010) :

1. Periklanan

Penawaran yang dilakukan oleh perusahaan sebagai pembuat produk yang berkaitan dengan produk, jasa, atau ide yang diiklankan kepada masyarakat umum, baik secara langsung, lisan maupun dengan pengelihatan (berupa berita).

\section{Publisitas}

Pemberian Informasi barang atau organisasi/perusahaan yang disebar luaskan ke masyarakat dengan cara membuat berita yang mempunyai arti yang menjual dan mengesankan atau sering di ingat.

\section{Personal selling}

model penjualan yang langsung bertatap muka antara si penjual dengan calon pembeli. penjual akan berkomunikasi secara persuasif pada calon pembeli dan akan menarik minat dari lawan bicaranya agar orang tersebut berminat atau mau membeli produk yang di jualnya.

\section{Sales promotion}

merupakan bentuk promosi dimana sang penjual akan melakukan peragaan, pertunjukkan,pameran, dan demonstrasi atau bentuk lainnya, dan dilakukan secara terus menerus atau berkesinambungan.

\section{Kepuasan}

Dalam penelitian ini ada beberapa pengertian kepuasaan menurut ahlinya, adalah sebagai berikut :

a.Kotler (2007) Kepuasan merupakan perpaduan antara perasaan senang dan kecewa konsumen setelah membandingkan kinerja produk yang diperkirakan dengan hasil yang diharapkan. 
b.Blackwell et al. (2006) mendefinisikan bahwa kepuasan konsumen merupakan hasil evaluasi purnabeli dimana hasilnya melampaui ekspektasi konsumen.

c.Bennet dan Rundle-Thiele, 2004 : menjelaskan kepuasan merupakan bentuk usaha perusahaan untuk memenuhi kebutuhan konsumen dan memenuhi keinginannya.

d.Reichheld dan Sasser (dalam Lee et al. 2001) menyebutkan kepuasan akan menciptakan pelanggan yang mana pelanggan ini tidak akan berpindah ke perusahaan lain.

e.Fornel (dalam Lee et al., 2001) mengungkapkan, menciptakan kkepuasan pelanggan adalah untuk meningkatkan tingkat retensinya.

Indikator kepuasan menurut lupiyoadi 2001:158:

1. Kualitas produk adalah kemampuan produk atau barang secara bentuk dan manfaat, mampu memberikan kepuasan kepada penggunanya, atau manfaatnya melebhi ekspektasi pengguna barang trersebut.

2. Kualitas pelayanan merupakan kemampuan perusahaan memberikan jasa atau layanan sesuai dengan apa yang diharapkan oleh pengguna jasa atau layanan.layanan yang dimaksud tidak hanya dari pegawai perusahaan tetapi juga dari segi fasilitas dan jaminan.

3. Emosional merupakan kepuasan yang diperoleh berasal dari nilai sosial yang membuat pelanggan menjadi puas terhadap merek tertentu.

4. Harga adalah sejumlah uang yang ditetapkan untuk suatu produk atau jasa atas kesepakatan antara pembeli dan penjual.

5. Biaya adalah sejumlah uang yang harus dikeluarkan sebagai imbalan atas sesuatu hal yang telah terjadi atau yang telah dilakukan.

\section{METODE PENELITIAN}

\section{Jenis penelitian}

Jenis Penelitian ini adalah Asosiatif, yaitu menjelaskan pengaruh dua variabel atau lebih. Dengan menggunakan metode survei, yang dilakukan fokus pada pengumpulan data yang memiliki informasi tertentu sehingga memungkinkan peneliti untuk menyelesaikan masalah.

\section{Populasi, dan Sampel Penelitian}

Populasi dalam penelitian ini adalah konsumen yang pernah melakukan potong rambut di laki lucky barbershop yang jumlahnya tidak diketahui pasti (unknown population). Sampel yang digunakan untuk mendukung penelitian ini adalah 96 responden dengan tehnik 
purposive sampling. Dalam penelitian ini sampel yang di ambil adalah konsumen yang pernah berkunjung langsung dan pernah menggunakan jasa potong rambut di laki lucky barbershop.

\section{Analisis Data}

a. Uji Validitasdan Uji Reabilitas

Untuk mengukur valid tidaknya kuesionermaka dilakukan uji validitas. Kuesioner yang mampu mengungkap sesuatu yang akan diukur dengan ambang batas 0,30 maka dikatakan kuisioner itu valid.

Tabel 1. Uji Validitas

\begin{tabular}{|c|c|c|c|c|}
\hline NO. & INDIKATOR & rhitung & rtabel & $\begin{array}{c}\text { Cronbach's } \\
\text { Alpha }\end{array}$ \\
\hline 1. & $\begin{array}{l}\text { Experiential marketing } \\
\text { E.M } 1 \\
\text { E.M } 2 \\
\text { E.M } 3 \\
\text { E.M } 4 \\
\text { E.M } 5 \\
\text { E.M } 6 \\
\text { E.M } 7 \\
\text { E.M } 8 \\
\text { E.M } 9 \\
\text { E.M } 10 \\
\text { E.M } 11 \\
\text { E.M } 12 \\
\text { E.M } 13 \\
\text { E.M } 14 \\
\text { E.M } 15 \\
\end{array}$ & $\begin{array}{l}, 570 \\
, 488 \\
, 312 \\
, 495 \\
, 624 \\
, 598 \\
, 627 \\
, 587 \\
, 466 \\
, 653 \\
, 595 \\
, 602 \\
, 584 \\
, 678 \\
, 708 \\
\end{array}$ & ,300 & Valid \\
\hline 2. & $\begin{array}{l}\text { PROMOSI } \\
\text { Promosi } 1 \\
\text { Promosi } 2 \\
\text { Promosi } 3 \\
\text { Promosi } 4 \\
\text { Promosi } 5 \\
\text { Promosi } 6 \\
\text { Promosi } 7 \\
\text { Promosi } 8 \\
\text { Promosi } 9 \\
\text { Promosi } 10 \\
\text { Promosi } 11 \\
\text { Promsi } 12\end{array}$ & $\begin{array}{l}, 569 \\
, 328 \\
, 550 \\
, 599 \\
537 \\
664 \\
, 667 \\
, 727 \\
, 641 \\
, 500 \\
, 519 \\
, 667\end{array}$ & ,300 & 0,821 \\
\hline
\end{tabular}


3. KEPUASAN KONSUMEN

$\begin{array}{llll}\text { Kepuasan konsumen 1 } & , 642 & \\ \text { Kepuasan Konsumen 2 } & , 687 & \\ \text { Kepuasan Konsumen 3 } & , 641 & \\ \text { Kepuasan Konsumen 4 } & , 642 & \\ \text { Kepuasan Konsumen 5 } & , 694 & \\ \text { Kepuasan Konsumen 6 } & , 706 & \\ \text { Kepuasan Konsumen 7 } & , 628 & , 300 \quad \text { Valid } \\ \text { Kepuasan Konsumen 8 } & , 512 & \\ \text { Kepuasan Konsumen 9 } & , 674 & \\ \text { Kepuasan Konsumen 10 } & , 500 & \\ \text { Kepuasan konsumen 11 } & , 650 & \\ \text { Kepuasan Konsumen 12 } & , 675 & \\ \text { Kepuasan Konsumen 13 } & , 624 & \\ \text { Kepuasan Konsumen 14 } & , 653\end{array}$

Sumber : data primer diolah 2020

Hasil uji validitas, bahwa item dari instrument X1 dan X2 memiliki nilai diatas 0,300, dan dinyatakan valid. tetapi pada variable kepuasan konsumen yaitu pada item pernyataan ke 15, memiliki nilai kurang dari 0,300, sehingga tidak dnyatakan valid. dalam halini, peneliti tetap melanjutkan analisis dengan hanya menggunakan item kepuasan konsumen sebanyak 14 pernyataan seperti pada table 1 di atas. Selanjutnya menurut Nunnally suatu instrument dapat dikatakan handal apabila memiliki koefisien keandalan $(\alpha) \geq 0,60$. Hasil pengujian reabilitas untuk instrument variabel Experiential marketing, promosi dan kepuasan konsumen dengan menggunakan cronbach alpha adalah sebagai berikut :

Tabel 2. Uji Reliabilitas

\begin{tabular}{lccc}
\hline Variabel penelitian & Cronbach alpha & Batas normal & Keterangan \\
\hline Experiential marketing & 0,855 & & \\
Promosi & 0,821 & 0,6 & Reliabel \\
Kepuasan konsumen & 0,888 & & \\
\hline
\end{tabular}

Sumber :data primer diolah 2020 
Dari tabel tersebut dapat diketahui bahwa seluruh instrument kuesioner yang digunakan yaitu meliputi variabel experiential marketing, promosi dan kepuasan konsumen semuanya menunjukkan bahwa instrument tersebut semuanya reliabel.

\section{Hasil dan pembahasan}

\section{Uji Regresi linier berganda}

Analisis regresi linier berganda adalah hubungan secara linear antara dua atau lebih

Tabel 3. Uji regresi Berganda

\begin{tabular}{|cc|c|c|c|c|c|}
\hline \multirow{2}{*}{ Model } & \multicolumn{2}{|c|}{ Unstandardized Coefficients } & $\begin{array}{c}\text { Standardized } \\
\text { Coefficients }\end{array}$ & $\mathrm{t}$ & \multirow{2}{*}{ Sig. } \\
\cline { 2 - 4 } & $\mathrm{B}$ & Std. Error & Beta & & \\
\hline \multirow{2}{*}{1} & (Constant) & 7.353 & 4.237 & & 1.735 & .086 \\
& TX1 & .363 & .117 & .352 & 3.088 & .003 \\
& & .571 & .143 & .456 & 3.997 & .000 \\
\hline
\end{tabular}

Sumber :data primer diolah 2020

Persamaan regresi linier berganda $\mathrm{Y}=\mathrm{Y}=7.353+0,363 \times 1+0,571 \times 2$.

Konstanta $=\mathrm{a}=7.353$, artinya jika experiential marketing dan promosi atau sama dengan nol maka kepuasan konsumen pada Laki lucky barbershop akan naik sebesar 7.353. Koefisien variabel $\mathrm{b} 1=0,363$, artinya jika experiential marketing naik sebesar 1 dimana promosi konstan, maka kepuasan konsumen pada Laki lucky barbershop naik sebesar 0,363 .

Koefisien variabel b2 $=0,571$, artinya jika promosi naik sebesar 1 dimana experiential marketing konstan, maka promosi pada Laki lucky barbershop naik sebesar 0,571.

\section{koefisien korelasi}

Tabel 4. Koefisien Korelasidan Koefisien Determinasi

\begin{tabular}{|c|c|c|c|c|}
\hline Model & $\mathrm{R}$ & R Square & Adjusted R Square & $\begin{array}{c}\text { Std. Error of the } \\
\text { Estimate }\end{array}$ \\
\hline 1 & $.770 \mathrm{a}$ & .592 & .584 & 4.291 \\
\hline
\end{tabular}

Sumber :data primer diolah 2020 
Berdasarkan hasil nilai koefisien korelasi yaitu sebesar 0,770. Artinya tingkat keeretan hubungan antara Experietial marketing dan promosi terhadap kepuasan konsumen pada Laki lucky barbershop sebesar 0,770. Dan pada interpretasi koefisien korelasi adalah kuat karena berada pada interval korelasi 0,60-0,799.

\section{Koefisien determinasi}

Berdasatkan tabel analisis diatas nilai koefisien determinasi linier berganda yaitu sebesar 0,592. Artinya kontribusi pengaruh Experiential marketing dan promosi terhadap kepuasan konsumen pada Laki lucky barbershop sebesar 59,2\%, sedangkan sisanya 0,\% kepuasan konsumen dipengaruhi oleh variabel-variabel lainnya yang tidak diteliti dalam penelitian ini.

\section{Uji t (parsial)}

Tabel 5. Uji Parsial

\begin{tabular}{|c|c|c|c|c|c|c|}
\hline & \multirow[t]{2}{*}{ Model } & \multicolumn{2}{|c|}{ Unstandardized Coefficients } & \multirow{2}{*}{$\begin{array}{l}\text { Standardized } \\
\text { Coefficients } \\
\text { Beta }\end{array}$} & \multirow[t]{2}{*}{$\mathrm{t}$} & \multirow[t]{2}{*}{ Sig. } \\
\hline & & $\mathrm{B}$ & Std. Error & & & \\
\hline \multirow{3}{*}{1} & (Constant) & 7.353 & 4.237 & & 1.735 & .086 \\
\hline & TX1 & .363 & .117 & .352 & 3.088 & .003 \\
\hline & TX2 & .571 & .143 & .456 & 3.997 & .000 \\
\hline
\end{tabular}

Sumber :data primer diolah 2020

Berdasarkan table hasil analisis diatas dapat disimpulkan bahwa experiential marketing dan promosi secara personal memberikan pengaruh terhadap kepuasan konsumen. besarnya pengaruh masing masing sebesar 3,088 untuk eksperiental marketing dan 3,997 untuk promosi. Hasil analisis juga menunjukkan bahwa pengaruh promosi lebih besar dibandingkan dengan pengaruh eksperiental marketing. 
Uji f (simultan)

Tabel 6. Uji F

\begin{tabular}{|c|c|c|c|c|c|c|}
\hline \multicolumn{7}{|c|}{ ANOVAa } \\
\hline & Model & $\begin{array}{l}\text { Sum of } \\
\text { Squares }\end{array}$ & df & Mean Square & $\mathrm{F}$ & Sig. \\
\hline \multirow{3}{*}{1} & Regression & 2488.977 & 2 & 1244.489 & 67.590 & $.000 \mathrm{~b}$ \\
\hline & Residual & 1712.356 & 93 & 18.412 & & \\
\hline & Total & 4201.333 & 95 & & & \\
\hline
\end{tabular}

a. Dependent Variable: TY

b. Predictors: (Constant), TX2, TX1

Sumber :data primer diolah 2020

Hasil analisis menunjukkan bahwa experiential marketing dan promosi secara serentak berpengaruh positif dan signifikan terhadap kepuasan konsumen karena nilaif $\mathrm{F}$ sebesar 67,590 lebih besar dari F tabel sebesar 3,09.

\section{KESIMPULAN DAN SARAN}

Berdasarkan hasil analisis dan penelitian dapat disimpulkan bahwa :

1. Experiential marketing dan promosi berpengaruh secara parsial terhadap kepuasan konsumen. Promosi memberikan pengaruh yang lebih besar kepada kepuasan konsumen, artinya, konsumen laki lucky barbershop tetap membutuhkan promosi untuk kepuasannya, baik itu promosi dalam bentuk verbal maupun visual, baik itu promosi langsung maupun promosi lewat media.

2. Hasil analisis lainnya menunjukkan bahwa experiential marketing dan promosi secara serentak berpengaruh positif dan signifikan terhadap kepuasan konsumen pada Laki lucky barbershop.keduanya memberikan dampak yang baik untuk laki lucky barbershop, jadi harus tetap dijalankan terus.

Saran :

1. Sebaiknya pihak laki lucky barbershop perlu meningkatkan dan memberikan kepuasan bagi konsumennya dengan tindakan dan kegiatan pelayanan yang ramah dan menyenangkan terhadap konsumen dan akan semakin menarik konsumen untuk berkunjung kembali.Tingkatkan juga untuk pemberian pengalaman yang berkesan, nilai ekpsperiental marketingnya lebih kecil dibanding promosi. 
2. Faktor lain yang harus di tingkatkan adalah periklanan, mengingat usaha barbershop adalah usaha baru di bima dan menciptakan pola pikir baru pada masyarakat bima, agar mau beralih dari salon potong rambut biasa ke salon potong rambut barbershop.

\section{DAFTAR PUSTAKA}

Andreani, Fransisca. Experiential Marketing. Jurnal Manajemen Pemasaran. 2(2),1-8.

Bennet, R. Dan Rundle-Theile S. (2004), Costumer Satisfaction Should not be the only goal. Journal of services Marketing, Vol. 18 No. 7pp. 514-523.

Blackwell, R.D., Miniard, P. W., dan Engel J.F (2006), Consumer Behavior, 10th ed. Thomson, Singapore.

M. Mursid, (2010), Manajemen Pemasaran/oleh.- - Ed. 1, Cet. 6. Jakarta : Bumi Aksara.

Canon, Perreault \& McCarthy. 2009. Pemasaran Dasar Pendekatan Manajerial Global. Buku 2 Edisi 16, Jakarta.

Honanta, C.R. dan Anandya, D. (2010), Experiential Marketing, Customer Satisfaction, Behavioral Intention: Timezone Game Center Surabaya. International ConferenceBusiness and Economic, April, pp. 1-6.

Hejaksumana, Valentino, Sugiharto, Sugiono. (2014). Analisis Pengaruh Experiential Marketing Terhadap Pembelian Ulang Konsumen The Vintage (House of Bovin andLynette) Surabaya. Jurnal Manajemen Pemasaran Petra. 2(1),1-14.

Handal, Nehemia S. (2010). Analisis Pengaruh Experiential Marketing Terhadap Loyalitas. JurnalManajemen Universitas Diponegoro.

Kotler, Philip. (2009). Manajemen Pemasaran. Jakarta : Macanan Jaya Cemerlang

Liljander, V. Dan Strandvik, Y. (1997), Emotions in Service Satisfaction. International Journal of Service Industry Management, 8, pp. 148-169.

Lupiyoadi, Rambat. 2001. Manajemen pemasaran. Salemba empat Jakarta. Manajemen pemasaran/oleh M. Mursid.--Ed. 1,Cet. 6.--Jakarta: Bumi Aksara, 2010. $\mathrm{X}, 136 \mathrm{hlm}: 24 \mathrm{~cm}$.

Manajemen pemasaran/ oleh M. Mursid.--Ed. 1, Cet. 6.--Jakarta: Bumi Aksara, 2010. $\mathrm{X}, 136 \mathrm{hlm} ; 24 \mathrm{~cm}$.

Nunes, P.E. dan Cespedes, F.V. (2003), The Customer Has Escaped. Harvard Business Review,81,pp.96-105

Reichheld, F.F. dan Sasser, Jr., W.E. (1990), Zero Defections. Quality Comes to Services. Harvard Business Review, 68, pp.105-111. 
Suryadi, Didih, 2011. Promosi Efektif menggugah minat \& Loyalitas Pelanggan. Penerbit PT Suka Buku, Jakarta Selatan.

Schmitt, B. (1999), Experiential Marketing. Journal of Marketing Management, 15, 1-3, pp. 53-67. 